\title{
Microwave Activated Synthesis of Benzalacetones and Study of Their Potential Antioxidant Activity Using Artificial Neural Networks Method
}

\author{
Anita Maria Rayar ${ }^{1}$, Elizabeth Goya Jorge ${ }^{2}$ Stephen Jones Barigye ${ }^{3}$, María Elisa Jorge \\ Rodríguez $^{2}$, Clotilde Ferroud ${ }^{1}$ and Maite Sylla Iyarreta Veitía ${ }^{1 *}$ \\ 1 Equipe de Chimie Moléculaire du Laboratoire CMGPCE, EA 7341, Conservatoire national des \\ arts et métiers, 2 rue Conté, 75003, Paris; anitarayar@hotmail.fr (A.M.R), \\ clotilde.ferroud@cnam.fr (C.F.),maite.sylla@cnam.fr (M.S.-I.V.) \\ 2 Pharmacy Department, Faculty of Chemistry, Central University "Marta Abreu" of Las \\ Villas, C-54830 Santa Clara, Cuba; egoyaj@gmail.com, elisajorge@yahoo.es \\ 3 Department of Chemistry, Federal University of Lavras, P.O. Box 3037, 37200-000 Lavras, \\ MG, Brazil; sjbarigye@gmail.com
}

* Author to whom correspondence should be addressed; E-Mail: maite.sylla@cnam.fr; Tel.: +33-1-58 8084 82; Fax: +33-1-40 272584.

Published: 4 December 2015

\begin{abstract}
The $\alpha, \beta$-unsaturated ketones known as benzalacetones are an interesting class of compounds frequently used as key intermediates in organic synthesis. Due to their conjugated system, benzalacetone and derivatives have been described as radical scavengers with potential antioxidant properties. We report here a simple and direct method to prepare functionalized $\alpha, \beta$ unsaturated ketones via a microwaves activated Claisen-Schmidt reaction. The experimental protocol developed selectively produces benzalacetones without self-condensation product in very short reaction times and good yields. Interested in the biological properties of benzalacetones, we also studied the antioxidant potential of these compounds using an in silico study based on the DPPH • radical scavenging ability. The built mathematical model was based on the 0-3D DRAGON molecular descriptors and the artificial neural networks technique showing a correlation coefficient for the training $\operatorname{set}\left(R^{2}\right)=0.71$, an external correlation coefficient $\left(Q_{\text {ext }}^{2}\right)=0.65$. Unfortunately, the results obtained in the in-silico study revealed that
\end{abstract}


synthesized benzalacetones have no antioxidant activity. The predicted results have been confirmed experimentally by an in vitro assay of DPPH• scavenging capacity.

Keywords: benzalacetones; artificial neural networks; antioxidant; QSAR; DPPH; free radical scavengers, microwaves-assisted synthesis

\section{Introduction}

As part of our studies involving the synthesis of bioactive compounds structurally related with the coumarin skeleton we have recently focused our attention on the synthesis of $\alpha, \beta$-unsaturated ketones known as benzalacetones, which possess interesting properties for organic synthesis. Due to their conjugated system, benzalacetone and derivatives have been described as radical scavengers with potential antioxidant properties [1]. Various methods of synthesis for this type of compounds have been described in the literature. The Claisen-Schmidt is one of the simplest condensation methods. This reaction is typically catalyzed by acids $\left(\mathrm{AlCl}_{3}\right.$ or $\left.\mathrm{HCl}\right)$ and more often by bases with or without solvent at room temperature or under conventional heating [2-4]. In order to increase the yield and to avoid the formation of byproducts, several protocols relative to ClaisenSchmidt condensation have also been reported using different catalysts, sonochemical activation or microwaves irradiation. However, in all these conditions, side reactions start decreasing the yield of the desired product and entail further purification steps [5-20]. Consequently, we were particularly interested in developing an efficient preparation of benzalacetones from acetone and aromatic substituted aldehydes in basic conditions under microwave-activation.

Secondly we were interested in the study of the antioxidant activity of synthesized benzalacetones. To achieve our goal we developed an in silico study using the OD-3D DRAGON molecular descriptors (MDs) and the artificial neural networks (ANN) method. The ANN is one of the artificial intelligence techniques applied to Quantitative Structure Activity Relationships (QSAR) evaluations. In this study we develop an ANN in order to relate scavenging ability of the DPPH $\bullet$ radical and molecule features defined by established MDs. Finally the theoretical results were confirmed experimentally by the in vitro assay of $\mathrm{DPPH} \bullet$ scavenging capacity.

\section{Results and Discussion}

2.1 Synthesis

Microwave activation for the synthesis of benzalacetones has not been widely described in the literature. Kappe et al reported the aldol condensation of $p$-methoxybenzaldehyde with acetone using microwave activation but could not prevent self-condensation. [21]

As a wide variety of aryl aldehydes is commercially available, microwave activation would provide a higher degree of flexibility with respects to functional groups which may be introduced in the benzalacetone skeleton. The details of the synthesis were previously described by our group Figure 1[22].

Following our interest in establishing an efficient, rapid and selective access to benzalacetones and considering our results previously obtained under conventional heating (dibenzalacetone formation in yields between 4- 
39\%), the Claisen-Schmidt condensations were carried out under controlled microwave activation. The reactions were performed with 1.5 equiv of $\mathrm{NaOH}$, in a Discover ${ }^{\mathrm{TM}}$ microwave synthesizer. The compounds were mixed in a sealed microwave reaction tube and irradiated for 10 to 30 minutes $(5 \mathrm{~W})$ with stirring at $50{ }^{\circ} \mathrm{C}$ or $40^{\circ} \mathrm{C}$. After irradiation, reactions were controlled by GC-MS analysis, and the purity of the desired products was evaluated by NMR spectroscopy. All synthetic details of microwave activation procedure and the extension of these conditions to the synthesis of various benzalacetones have been previously described by our research group [22].

The use of microwave activation resulted in a dramatic decrease of reaction times. The reactions were generally achieved within 10-15 min. The desired compounds were isolated with excellent yields (typically higher than 79\% and often quantitative) and clean enough to be further used without any purification. These microwave-assisted condensation reactions could be "directly scalable". Identical yields were obtained on $50 \mathrm{mg}$ and $500 \mathrm{mg}$ scale [22].

\subsection{Modeling}

The 0D-3D DRAGON MDs were computed for an in-house dataset of 1329 compounds whose DPPH• scavenging capacity has been experimentally determined and reported in the literature. Using a wrapper based variable selection procedure; a subset of 14 variables was obtained and posteriorly used as the ANN input. The mathematical model constructed showed a correlation coefficient $\left(R^{2}\right)$ for the training set of 0.71 . The predictive ability of the models was assessed using the external validation procedure yielding a correlation coefficient obtain $\left(Q_{\text {ext }}^{2}\right)$ of 0.65 . Both values are above the limits established for model acceptance, which is an indicator of the robustness and predictive power of the obtained MLP model.

\subsection{Prediction:}

Virtual screening allows for prior assessment of the potential bioactivity of chemical compounds, and thus providing key guidelines in posterior experimental work. In this study the MLP model previously obtained was used to predict the DPPH • scavenging capacity of a series of functionalized benzalacetones (Bzder). The results of the predictions are shown in Table 1.

As it can be noticed the Bz-der seem to be less effective in DPPH• radical capturing, since their values of $\mathrm{pIC}_{50}$ are much higher than the reference compound, butylated hydroxytoluene (BHT, experimental $\mathrm{pIC}_{50}$ of 2.10). The exception is 1-naphtalene, in which the substituent is benzene fused to the benzalacetone moiety ( $\mathrm{pIC}_{50}$ of 2.97).

According to conventional understanding of antioxidant activity, increasing of the number of phenolic hydroxyl groups enhances the compounds' antioxidant effectiveness. That's why many efforts have been carried out to synthesize antioxidants containing phenolic hydroxyl groups [23].

Consequently, we suggest that low antioxidant activity of the benzalacetones studied here could be due to the absence of hydroxyl groups linked to the aromatic system. On the other hand, several compounds used as references in the evaluation of antioxidant activity contain the phenolic group, for instance, Trolox, Gallic Acid and BHT.

2.3. In vitro Assay: The result obtained with the in silico modeling was corroborated using the experimental study of $\mathrm{DPPH} \bullet$ scavenging capacity for the non-substituted compound, $(E)$ 4-phenylbut-3-en-2-one whose $\mathrm{pIC}_{50}$ was previously predicted $(4,21)$, and experimentally 
obtained (4.97). These values of $\mathrm{IC}_{50}$ were indicative of very low scavenging activity, compared with the value obtained for BHT (2.10). The results demonstrate the predictive power of the designed ANN model and its possible applicability in the study of benzalacetones as antioxidant compounds.
These results also suggest the need to synthesize benzalacetone derivatives bearing hydroxyl groups which would improve the antioxidant activity of these compounds

Figure 1: Preparation of benzalacetones under microwaves conditions

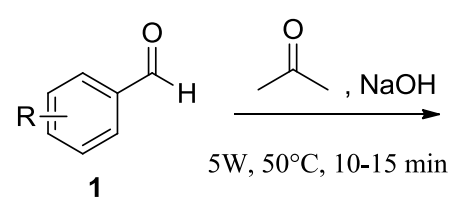

$\mathrm{R}=\mathrm{H}, 4-\mathrm{Me}, 4-t-\mathrm{Bu}, 4-\mathrm{F}, 4-\mathrm{Br}, 4-\mathrm{OMe}, 3-\mathrm{Cl}$, 3,4-diOMe, 2,5- $\mathrm{NO}_{2}, \mathrm{Cl}$, phenyl<smiles>CC(=O)/C=C/c1cc#[R]cc1</smiles>

$80-100 \%$<smiles>[R][R]1ccc(/C=C/C(=O)/C=C/c2cc#[R]cc2)cc1</smiles>

$0 \%$

Table 1: Predictions of the $\mathrm{pIC}_{50}$ values for $\mathrm{Bz}-\mathrm{der}$

\begin{tabular}{|l|l|l|l|}
\hline Origin & 3D Structures & Predict pIC50 \\
\hline Bz-der & Benzalacetone & \\
\hline Bz-der & 4-OMeBenzalacetone & \\
\hline Bz-der & 4-MeBenzalacetone & \\
\hline
\end{tabular}




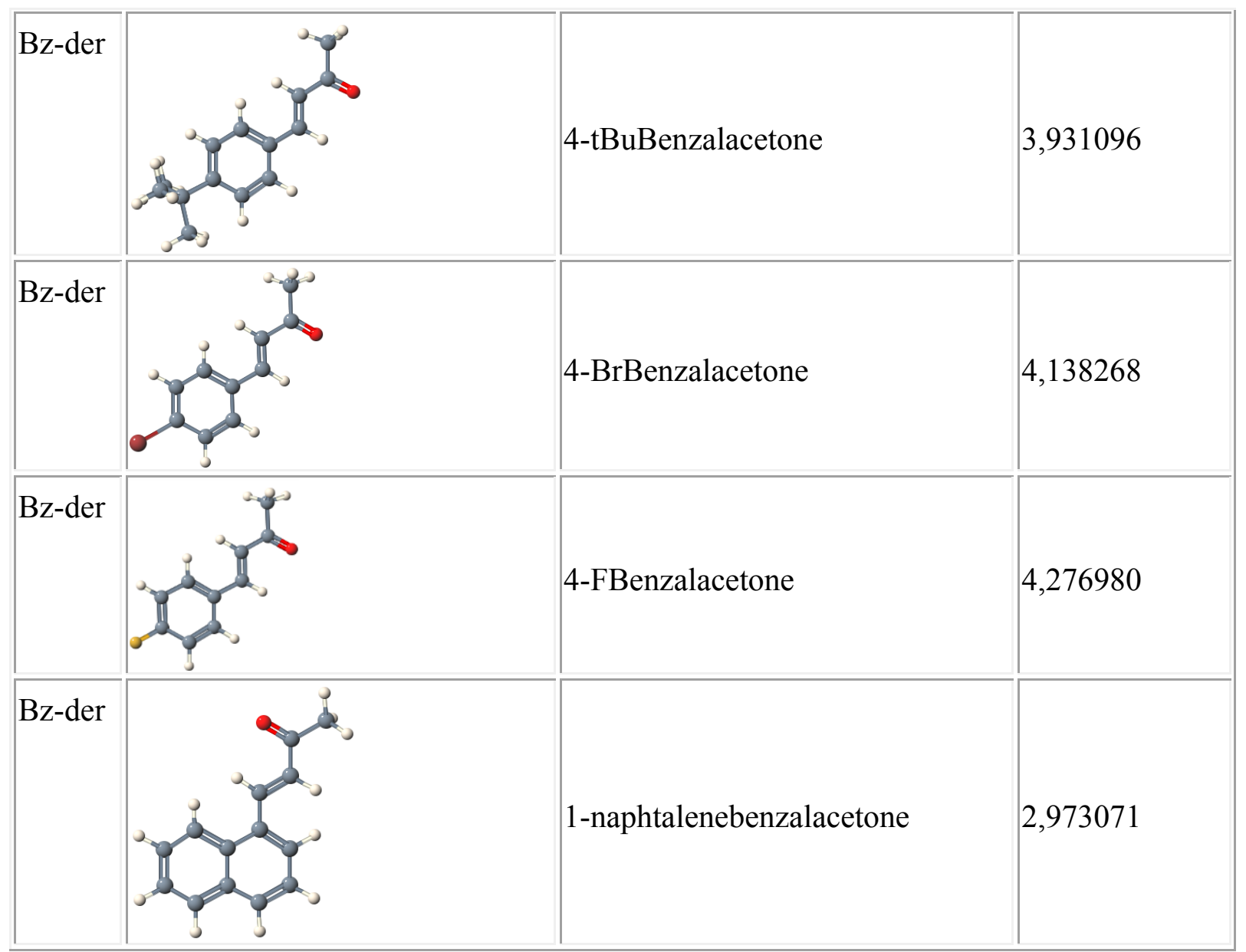

\section{Materials and Methods}

3.1 General procedure for the microwaveassisted syntheses

In a capped $10 \mathrm{~mL} \mathrm{MW}$-vessel, the aldehyde (50 mg, 1 equiv) and acetone (13.6 equiv) were mixed and then an aqueous solution of $\mathrm{NaOH}$ $\left(0.6 \mathrm{~g} / \mathrm{cm}^{3}\right.$ of water) was added. The tube was positioned in the irradiation cavity and the mixture was stirred and heated at the temperature $40 / 50{ }^{\circ} \mathrm{C}$ (measured with an IR temperature sensor), in the monomode microwave oven ( 5 W) for $10 / 15 \mathrm{~min}$. After completion, upon cooling to room temperature, the conversion was directly controlled by GC-MS analysis. The product was extracted with AcOEt. The organic layers were dried over anhydrous $\mathrm{MgSO}_{4}$, filtered and concentrated under reduced pressure to obtain the corresponding benzalacetone. The purity of the final products was controlled by NMR [22].

\subsection{In silico study}

Data: Experimental results of the scavenging ability of the DPPH $•$ radical (expressed as $\mathrm{IC}_{50}$ ) for 1329 molecules were extracted from over 170 scientific reports in the literature; and thus yielding a comprehensive and diverse database of compounds for the mathematical analysis. All the structures were optimized using the CORINA software. The response variable ( $\left.\mathrm{IC}_{50}\right)$ were transformed to their corresponding $\mathrm{pIC}_{50}$ values. Molecular Descriptors: The parameterization of the structures was performed using 3224 molecular descriptors implemented in the DRAGON software. A wrapper based variable selection procedure was used to obtain a subset of variables for the ANN building. 
Development of ANN model: The QSAR model was develop using as chemometric tool a Multilayer Perceptron Neural Network implemented in STATISTICA 8.0 software. For the modeling a Broyden-Fletcher-GoldfarbShanno algorithm was used as the optimization method; and the following network architecture was considered: fourteen inputs; eight neurons in hidden layer and one output.

Predictions of antioxidant activity: The benzalacetone derivatives were optimized following the same configurations previously used and the corresponding MDs computed.

3.3 In vitro $D P P H \bullet$ assay: The free radical scavenging activity of benzalacetone was measured using the stable DPPH radical, according to Blois' method [24]. Briefly, $0.1 \mathrm{mM}$ solution of $\mathrm{DPPH} \bullet$ in methanol was prepared and this solution (1 $\mathrm{mL})$ was added to sample solution in methanol (3 $\mathrm{mL})$ at different concentrations $(250-1250 \mu \mathrm{g} / \mathrm{mL})$. The mixture was shaken vigorously and left to stand for 30 min in the dark, and the absorbance was then measure at $517 \mathrm{~nm}$. Butylated hydroxytoluene (BHT) was used for comparison. Both determinations were due in triplicate. The capability to scavenge the $\mathrm{DPPH} \cdot$ radical was expressed as $\mathrm{IC}_{50}$ (concentration of antioxidant that produces $50 \%$ of absorbance inhibition)

\section{Conclusions}

In conclusion, an efficient and selective general method has been developed for the synthesis of benzalacetones via a Claisen-Schmidt reaction using microwaves activation. The desired compounds were obtained in shorter times and in almost all cases in quantitative yields. No further purification was required. Under microwaves activation, no dibenzalacetone formation has been observed except in the case of electron-withdrawing substituted aldehydes. Moreover, an ANN based model was developed to predict the antioxidant activity of the synthesized benzalacetones. Unfortunately, the insilico study showed that benzalacetones do not have antioxidant activity. Finally, the predicted results have been experimentally confirmed by the in vitro assay of $\mathrm{DPPH} \bullet$ scavenging capacity.

\section{Acknowledgments}

MENRT is gratefully acknowledged for the graduate fellowship awarded to Anita Rayar. The authors gratefully acknowledge support for part of this work through the program PYTHAGORAS II of EPEAEK II (MIS: 97436/073). We would like to thank Dr. C. Hansch and Biobyte Corp. 201 West 4th Street, Suite 204, Claremont, CA 91711, USA for free access to the C-QSAR program. The authors also thank the "Service de Coopération et d'Action Culturelle" of Embassy of France in Cuba for the financial support.

\section{Author Contributions}

The French team, A.M.R., M.S.-I.V. and C.F., is responsible for the synthesis and characterization of compounds, the Cuban team (E.G.R. and E.J.R.D.) and S.J.B. are responsible for the in silico study and the in vitro evaluation. All authors contributed to the drafting and revision of the article and approved the final version.

\section{Conflicts of Interest}

The authors declare no conflict of interest 


\section{References and Notes}

1. Handayani S.; Arty I.S. Synthesis of Hydroxyl Radical Scavengers from Benzalacetone and its Derivatives. J. Phys. Sci., 2008, 19; 61-68.

2. Drake N.L.; Allen P. Benzalacetone. J.Org. Synth. 1923, 3:17.

3. Rahman A.F.M.M.; Ali R.;Jahng Y.; Kadi A.A.A Facile Solvent Free Claisen-Schmidt Reaction: Synthesis of $\alpha, \alpha^{\prime}$-bis-(Substituted-benzylidene)cycloalkanones and $\alpha, \alpha^{\prime}$-bis-(Substituted-alkylidene) cycloalkanones. Molecules 2012, 17, 571-583.

4. Jayapal, M.R.; Prasad, K.S. and Sreedhar N.Y., Synthesis and characterization of 2,6-dihydroxy substituted chalcones using PEG-400 as a recyclable solvent. J. Pharm. Sci. Res. 2010, 2, 450-458.

5. Aguilera, A.; Alcantara, A. R.; Marinas, J. M.; Sinisterra, J. V. $\mathrm{Ba}(\mathrm{OH})_{2}$ as the catalyst in organic reactions, part XIV: Mechanism of Claisen-Schmidt condensation in solid-liquid conditions. Can. J. Chem. 1987, 65, 1165-1171.

6. Narender, T.; Papi Reddy, K. A simple and highly efficient method for the synthesis of chalcones by using borontrifluoride-etherate. Tetrahedron Lett. 2007, 48, 3177-3180.

7. Pal R. Ammonium chloride catalyzed microwave - assisted Claisen - Schmidt reaction between ketones and aldehydes under solvent - free conditions. IOSR J. App. Chem. (IOSR-JAC) 2013, 3, 74-80.

8. Kumar D.S.; Sandhu J.S. An efficient green protocol for the synthesis of chalcones by a Claisen Schmidt reaction using bismuth(III)chloride as a catalyst under solvent-free condition. Green Chem. Lett. Rev. 2010, 3, 283-286.

9. Deng G.; Ren T. Indium Trichloride Catalyzes Aldol-Condensations of Aldehydes and Ketones. Synth. Commun. 2003, 33, 2995-3001.

10. Iranpoor N.; Zeynizadeh B.; Aghapour A. Aldol Condensation of Cycloalkanones with Aromatic Aldehydes Catalysed with $\mathrm{TiCl}_{3}\left(\mathrm{SO}_{3} \mathrm{CF}_{3}\right)$. J. Chem. Res. 1999, S, 554-555.

11. Wang L.; Sheng J.; Tian H.; Han J.; Fan Z.; Qian C. A convenient synthesis of $\alpha$, $\alpha^{\prime}$-bis (substituted benzylidene) cycloalkanones catalyzed by $\mathrm{Yb}(\mathrm{OTf})_{3}$ under solvent-free conditions. Synthesis 2004, 3060-3064.

12. Zhang X.; Fan X.; Niu H.; Wang J. An ionic liquid as a recyclable medium for the green preparation of a, a'-bis (substituted benzylidene)cycloalkanones catalyzed by $\mathrm{FeCl}_{3} 6 \mathrm{H}_{2} \mathrm{O}$. Green Chem. 2003, 5, 267-269.

13. Sashidhara K.V.; Rosaiah J.N.; Kumar A. Iodine catalyzed mild and efficient method for the synthesis of chalcones. Synth. Commun. 2009, 39, 2288-2296.

14. Irie K.; Watanabe K-I. Catalysis of metal (II) acetate-2,2'-bipyridine complexes in the aldol condensations. Bull. Chem. Soc. Jpn. 1981, 54, 1195-1198.

15. Esmaeili AA; Tabas MS; Nasseri MA; Kazemi F. Solvent-Free Crossed Aldol Condensation of Cyclic Ketones with Aromatic Aldehydes Assisted by Microwave Irradiation. Monatsh. Chem. 2005, 136, 571-576.

16. Bogdal D.; Loupy A. Application of Microwave Irradiation to Phase-Transfer Catalyzed Reaction.

Org. Process. Res. Dev. 2008, 12, 710-722. 
17. Zheng M.; Wang L.; Shao J.; Zhong Q. A Facile Synthesis of $\alpha$, $\alpha^{\prime}$-bis(Substituted Benzylidene)cycloalkanones Catalyzed by bis(p-ethoxyphenyl)telluroxide(bmpto) Under Microwave Irradiation. Synth. Commun. 1997, 27, 351-354.

18. Nakano T.; Irifune S.; Umano S.; Inada A.; Ishii Y.; Ogawa M. Cross-Condensation Reactions of Cycloalkanones with Aldehydes and Primary Alcohols under the Influence of Zirconocene Complexes. J. Org. Chem. 1987, 52, 2239-2244.

19. Pal R.; Sarkar T.; Khasnobis S (2012) Amberlyst-15 in organic synthesis Arkivoc i: 570-609.

20. Gladkowski W.; Skrobiszewski A.; Mazur M.; Siepka M.; Pawlak A.; Obminska-Mrukowicz B.; Bialonska A.;Poradowski D.; Drynda A.; Urbaniak, M. Synthesis and anticancer activity of novel halolactones with $\beta$-aryl substituents from simple aromatic aldehydes. Tetrahedron 2013, 69, 10414-10423.

21. Viviano M; Glasnov TN; Reichart B.; Tekautz G.; Kappe C.O. A Scalable Two-Step Continuous Flow Synthesis of Nabumetone and Related 4-Aryl-2-butanones. Org. Process. Res. Dev. 2011, 15, 858-870.

22. Rayar A.; Sylla-Iyarreta Veitía M.; Ferroud, C. An efficient and selective microwave-assisted Claisen-Schmidt reaction for the synthesis of functionalized benzalacetones. Springer Plus 2015, 4, 221-226.

23. Gao-Lei X.; Zai-Qun L. Antioxidant effectiveness generated by one or two phenolic hydroxyl groups in coumarin-substituted dihydropyrazoles. Eur. J. Med. Chem. 2013, 68, 385-393.

24. Blois M.S. Antioxidant determinations by the use of a stable free radical. Nature. 1958, 181, 1199-1200.

(C) 2015 by the authors; licensee MDPI, Basel, Switzerland. This article is an open access article distributed under the terms and conditions defined by MDPI AG, the publisher of the Sciforum.net platform. Sciforum papers authors the copyright to their scholarly works. Hence, by submitting a paper to this conference, you retain the copyright, but you grant MDPI AG the non-exclusive and unrevocable license right to publish this paper online on the Sciforum.net platform. This means you can easily submit your paper to any scientific journal at a later stage and transfer the copyright to its publisher (if required by that publisher). (http://sciforum.net/about ). 